\title{
Digital analysis of the orbit using the non-referring method
}

\author{
Tomasz Lepich¹, Józefa Dąbek², Mieczysław Piechota³ ${ }^{3}$ Grzegorz Bajor ${ }^{1}$, Łukasz Aniszewski ${ }^{1}$, \\ Jarosław Markowski ${ }^{4}$
}

${ }^{1}$ Department of Human Anatomy, Medical University of Silesia, Katowice, Poland ${ }^{2}$ Department of Cardiology, Medical University of Silesia, Katowice, Poland ${ }^{3}$ Municipal Hospital, Tychy, Poland

${ }^{4}$ ENT Department, Medical University of Silesia, Katowice, Poland

Submitted: 6 November 2010

Accepted: 13 March 2011

Ach Med Sci 2014; 10, 1: 182-190

DOI: 10.5114 /aoms.2014.40744

Copyright (c) 2014 Termedia \& Banach

\section{Abstract}

Introduction: Anthropological analysis of the orbits using classic anthropometric instruments based on width and height measurements as well as orbital index allows for classification of orbits in terms of their shape, yet it has poor clinical application. Nowadays computer graphics enables a precise research technique implementing the latest achievements in digital technology and data recording. The aim of the study was to compare in let parameters of left and right orbits in male and female skulls by means of digital analysis techniques.

Material and methods: The analysis was carried out on 184 early medieval well-preserved skulls. The examined crania were fixed into Molisson's craniost at in the author's own modification. They were directed in space towards the Frankfurt plane and photographed in a frontal norm. Parameters describing the plane structure of the orbits were obtained through computer analysis, integrating raster and vector graphics of mathematical recordings of craniofacial structures.

Results: The research demonstrated some differences between male and female skulls. Parameters of right orbit like area, circumference, radius, excavation, circularity deviation and functional were statistically significant higher values in male skull. The following parameters of left orbit: area, circumference, reference circle radius, parameter describing height between two point (mf-ek), maximal width, maximal excavation in relation to median and mean, circularity deviation and functional were statistically significant higher parameter in the male group.

Conclusions: Orbit shape variability, and especially variability of the orbit in let, are highly important features for anthropologists and maxillofacial surgeons, hence the usefulness of the in let orbit shape digital analysis.

Key words: orbit, digital analysis.

\section{Introduction}

The orbit is one of the most complicated parts of the facial cranium. It is an anatomical structure in the upper and frontal part of the face. The base of the orbit is directed forward and slightly on the side. Their long axes converge backwards and upper from the sella turcica $[1,2]$. Anthropological analysis of the orbits is based on fundamental width [3-6] and height [3] measurements, as well as on the orbital index [3, 7]

\author{
Corresponding author: \\ Tomasz Lepich MD, PhD \\ Department \\ of Human Anatomy \\ Medical University of Silesia \\ 18 Medyków St \\ 40-252 Katowice-Ligota, \\ Poland \\ E-mail: lepich@sum.edu.pl
}


and it allows for their classification in terms of their shape. However, so far, such an analysis and its findings have been of limited clinical use. On the other hand, classic anthropometric methods are burdened with errors resulting from the way measuring devices are constructed and also from the investigator's experience. The construction and the way the anthropometric instruments are used restrict the possibility of applying them in patients' examination. Progress during the last decade in reconstructive surgery of the face, using artificial eyeballs in enucleated patients, justifies the necessity of further research in the domain of thorough metric analysis of the orbits pictured in computed tomography (CT) and magnetic resonance (MR) techniques. Computer graphics is a precise method using the latest achievements in digital data recording.

\section{Material and methods}

The analysis was conducted on 184 well-preserved early medieval skulls from archeological sites in Kije and Złota Pińczowa, being in the possession of the Warsaw University Archeology Institute. The mentioned archeological sites are depicted in the monograph by Zoll-Adamikowa [8]. The analysis was conducted only on the adultus and maturus crania which had been conserved as the calvarium (that is the skull without the mandible). The age of the skulls estimated on the basis of dentition and calcification of stitches ranged from 20 to 55 years $( \pm 5)$. The skulls were divided according to their sex into a male (105) and female (79) group. In order to obtain a repeatable and stable measuring position, the skulls were fixed into Molisson's craniostat in the author's own modification.

\section{Computer graphics methods in assessing the orbits}

Pictures of the crania were taken with a high resolution $(2272 \times 1704)$ digital camera, Camedia 4040. Digital pictures of the orbits were analyzed using the author's own application, Digital Image Cranio-Analyzer 2.0 (DICA 2.0), developed at the Silesian Medical University Anatomy Department, combining bit and raster $[9,10]$ simultaneous re-

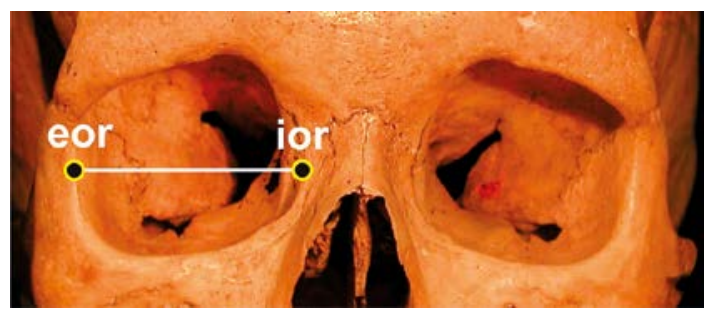

Figure 2. Distance between interorbitale and ectoorbitale: ior - interorbitale, eor - ectoorbitale cording. After fixing them on the Frankfurt line, the crania were photographed frontally from the distance of $50 \mathrm{~cm}$. To analyze the orbit pictures, the non-referring method was used. The following values were determined [10]: the surface area of the orbit in square millimeters $(P)$, orbit circumference $(O)$ being the orbit's contour in millimeters, and the center of gravity $\left(S_{s c}\right)$, which is the arithmetic mean of all orbit contour point coordinates. The discrete model, represented by a series of 360 temporary radii that equal the distance from the center of gravity to the points located on the orbit contour for the angles of 0 to $350^{\circ}$, was developed only after determining the center of gravity (Figures 1-6).

These are the radii determined next: temporary, median, of mean circle (Figure 1), of width: Seor-ior, Smf-ek, maximal orbit width in millimeters and height - Hmf-ek, Hmax. On the basis of these data maximal elevation (Wmax) and maximal excavation (Gmax) were generated and sorted according to the mean, median and circularity deviation in millimeters. The functional describing the examined orbit outline was determined by assuming that the distance between the cen-

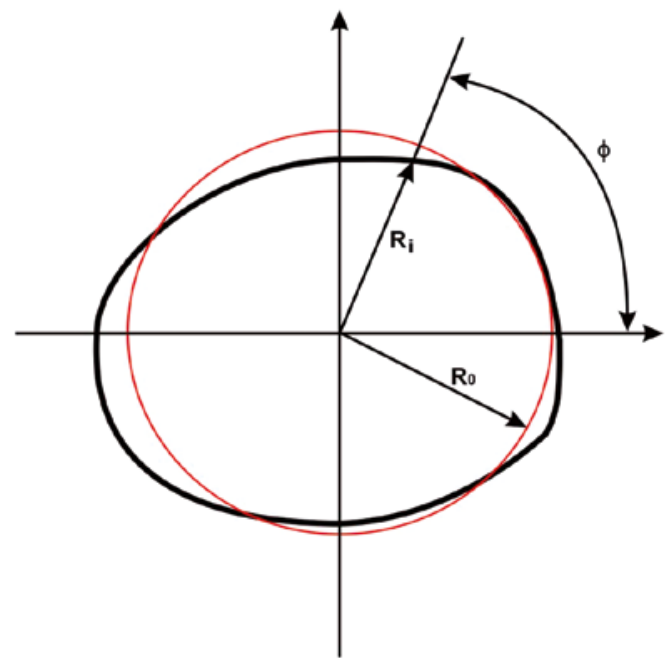

Figure 1. Discrete model of the orbit contour: $\phi-$ angle comprised in the interval $\langle 0,359\rangle$, $R_{i}$ - temporary radius of the examined outline, $R_{o}$ - reference circle radius; red color - reference circle, black color - orbit contour

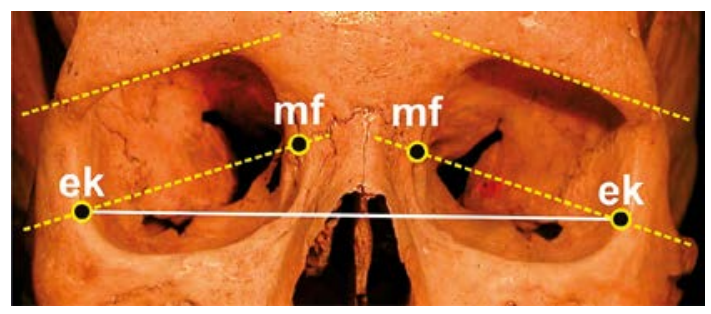

Figure 3. Distance between points of ectoconchion: $e k$ - ectoconchion, $m f$ - maxillofrontale 


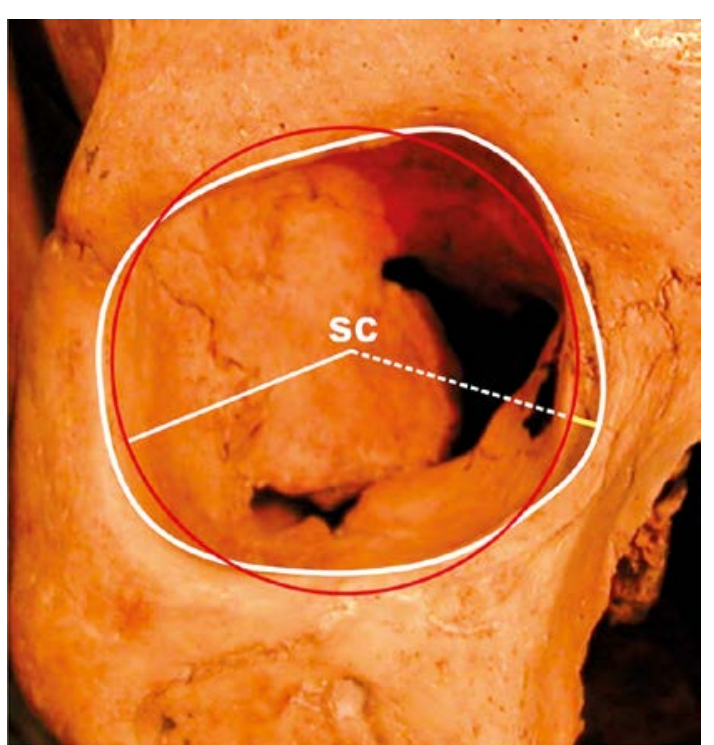

Figure 4. Maximal elevation: SC - orbit center of gravity; maximal elevation ( $W$ max)

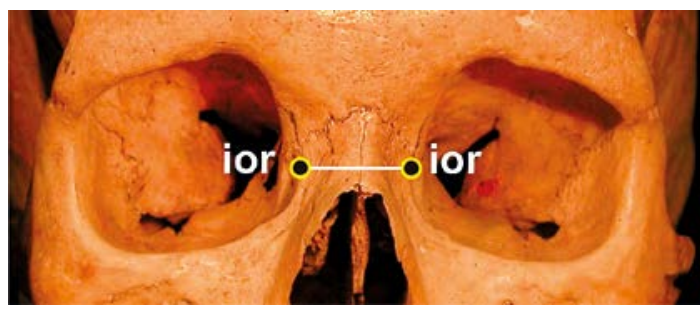

Figure 6. Distances between interorbitale points on both sides

ter of gravity and the point situated on the curve. This confirms the value of an angle ranging from 0 to 360 and is also based on discrete values of circularity deviations. All considered craniometric measurement values are given in millimeters, the angles in degrees and surface area is expressed in square millimeters. The examined parameters are the following: area $(P)$, circumference $(O)$, radii $\left(R_{m}\right.$, $R_{x}$ ), orbit width (Seor-ior, Smf-ek, Smax) and height (Hmf-ek, Hmax), excavation (Gmax Gmax $_{x}$ ) elevation: $W_{\max }$ and $W_{\max _{x}}$ circularity deviation (Z), functional $(F)$ and circularity index $(K)$.

\section{Statistical analysis}

The analysis was based on the Statistica program, by means of which it was possible to calculate the arithmetic mean and standard deviation for each feature in the male and female group. The outcome was presented in tables as arithmetic means \pm SD. The moduli are: arithmetic after the following formula: n-pr + zma-zma and geometric after $n$-pr $x$ zma-zma. Each value of arithmetic mean was divided by the value of a modulus and then multiplied 100 times. In order to evalu-

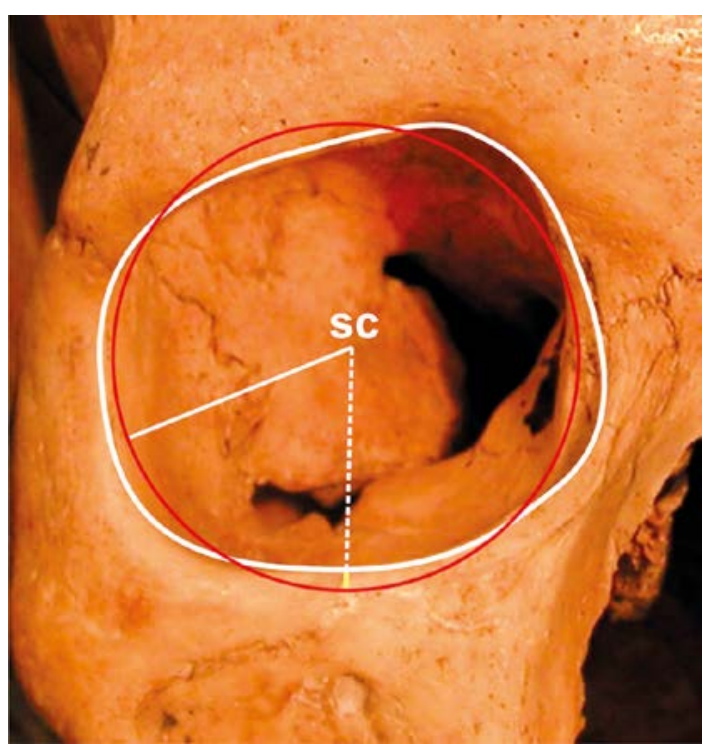

Figure 5. Maximal excavation: SC - center of gravity; maximal excavation (Gmax)

ate differences between the arithmetic mean in the two examined groups, the Student $t$-test for independent data was used. Before applying the test, all required conditions for parametric tests were thoroughly checked. The consistency of the empirical distribution for the examined variables with the normal distribution, separately for male and female skulls, was determined using the Kolmogorov-Smirnov test. The Levine test, in turn, examined the uniformity of variance. In the case of heterogeneous variance the Cochran-Cox test was applied. All data with abnormal distribution were transformed logarithmically with a decimal basis. If the transformed data continued to present abnormal distribution for a given variable in both groups, the non-parametric alternative for the Student $t$-test was applied - which is the Mann-Whitney $U$ test. To compare the differences in mean features for the left and right orbitals, the above-mentioned procedure was followed. Finally the Student $t$-test and the Mann-Whitney $U$ test were applied for the independent data.

\section{Results}

\section{Right orbit parameters in male and female skulls}

In our study the area $\left(P_{R}\right)$, circumference $\left(O_{R}\right)$, radius $\left(R_{R m}, R_{R x}\right)$, width (Seor-ior ${ }_{R}, S_{\text {Smf-ek }}$, Smax $\left._{R}\right)$ and excavation $\left(\operatorname{Gmax}_{R m}, \operatorname{Gmax}_{R x}\right)$ as well as circularity deviation and functional $\left(Z_{R}\right.$ and $\left.F_{R}\right)$ of the right orbit showed statistically significant higher values in male skulls in comparison to female skulls. Parameters of orbit height $\mathrm{Hmf}_{-} e \mathrm{k}_{R}$ and $H_{\max }$, as well as parameters of maximal elevation $W_{\max _{R m}}$ and $W_{\max _{R x}}$, did not show statistically significant differences between sexes (Table I). 
Table I. Parameters of size and shape of right orbit (RO)

\begin{tabular}{|c|c|c|c|c|c|}
\hline \multirow{2}{*}{$\begin{array}{l}\text { Parameters } \\
\text { RO }\end{array}$} & \multicolumn{2}{|c|}{$\hat{\sigma}$} & \multicolumn{2}{|c|}{$q$} & \multirow[t]{2}{*}{ Value of $p$} \\
\hline & $x$ & SD & $x$ & SD & \\
\hline$P_{R}\left[\mathrm{~mm}^{2}\right]$ & 1178.31 & 136.16 & 1120.22 & 119.28 & 0.002 \\
\hline$O_{R}[\mathrm{~mm}]$ & 124.76 & 7.14 & 121.50 & 6.60 & 0.001 \\
\hline$R_{R m}[\mathrm{~mm}]$ & 19.29 & 1.10 & 18.67 & 0.93 & 0.002 \\
\hline$R_{R x}[\mathrm{~mm}]$ & 19.13 & 1.10 & 18.66 & 0.99 & 0.003 \\
\hline Seor-ior $_{R}^{*}[\mathrm{~mm}]$ & 40.07 & 4.64 & 38.65 & 7.08 & 0.001 \\
\hline$S m f-e k_{R}[\mathrm{~mm}]$ & 39.75 & 2.51 & 38.26 & 2.41 & 0.001 \\
\hline $\operatorname{Smax}_{R}[\mathrm{~mm}]$ & 43.20 & 2.66 & 42.17 & 2.68 & 0.011 \\
\hline$H m f-e k_{R}[\mathrm{~mm}]$ & 34.12 & 2.30 & 33.78 & 2.22 & 0.322 \\
\hline $\operatorname{Hmax}_{R}[\mathrm{~mm}]$ & 35.93 & 2.73 & 35.45 & 2.43 & 0.224 \\
\hline$W_{\max }[\mathrm{mm}]$ & 3.06 & 0.88 & 3.12 & 0.97 & 0.671 \\
\hline$W_{\max }[\mathrm{mm}]$ & 3.22 & 0.76 & 3.13 & 0.81 & 0.456 \\
\hline $\operatorname{Gmax}_{R m}[\mathrm{~mm}]$ & 2.87 & 0.64 & 2.42 & 0.56 & 0.001 \\
\hline $\operatorname{Gmax}_{R x}[\mathrm{~mm}]$ & 2.71 & 0.53 & 2.40 & 0.49 & 0.003 \\
\hline$Z_{R}[\mathrm{~mm}]$ & 5.93 & 1.19 & 5.54 & 1.24 & 0.030 \\
\hline$K_{R}[\mathrm{~mm}]$ & 1.05 & 0.01 & 1.05 & 0.01 & 0.103 \\
\hline$F_{R}$ & 2.86 & 1.15 & 2.42 & 1.15 & 0.011 \\
\hline
\end{tabular}

$\hat{\delta}$ - male skulls, + - female skulls, $X$ - arithmetic mean, SD - standard deviation, $p$ - significance level. Statistically significant values for Student $t$-test and Mann-Whitney* $U$ test $(p<0.05)$

Table II. Right orbit size and shape parameters (RO), normalized results in accordance with arithmetic modulus

\begin{tabular}{|c|c|c|c|c|c|}
\hline \multirow{2}{*}{$\begin{array}{l}\text { Parameters } \\
\text { RO }\end{array}$} & \multicolumn{2}{|c|}{$\hat{0}$} & \multicolumn{2}{|c|}{ 우 } & \multirow[t]{2}{*}{ Value of $p$} \\
\hline & $x$ & SD & $x$ & SD & \\
\hline$P_{R}\left[\mathrm{~mm}^{2}\right]$ & 685.98 & 79.27 & 689.37 & 73.40 & 0.002 \\
\hline$O_{R}[\mathrm{~mm}]$ & 72.63 & 4.16 & 74.77 & 4.06 & 0.001 \\
\hline$R_{R m}[\mathrm{~mm}]$ & 11.23 & 0.64 & 11.49 & 0.57 & 0.002 \\
\hline$R_{R x}[\mathrm{~mm}]$ & 11.14 & 0.64 & 11.48 & 0.61 & 0.003 \\
\hline Seor-ior $_{R}^{*}[\mathrm{~mm}]$ & 23.33 & 2.70 & 23.78 & 4.36 & 0.001 \\
\hline$S m f-e k_{R}[\mathrm{~mm}]$ & 23.14 & 1.46 & 23.54 & 1.48 & 0.001 \\
\hline $\operatorname{Smax}_{R}[\mathrm{~mm}]$ & 25.15 & 1.55 & 25.95 & 1.65 & 0.011 \\
\hline$H m f-e k_{R}[\mathrm{~mm}]$ & 19.86 & 1.34 & 20.79 & 1.37 & 0.322 \\
\hline $\operatorname{Hmax}_{R}[\mathrm{~mm}]$ & 20.92 & 1.59 & 21.82 & 1.50 & 0.224 \\
\hline $\operatorname{Wmax}_{R m}[\mathrm{~mm}]$ & 1.78 & 0.51 & 1.92 & 0.60 & 0.671 \\
\hline$W_{\max _{R x}}[\mathrm{~mm}]$ & 1.87 & 0.44 & 1.93 & 0.50 & 0.456 \\
\hline $\operatorname{Gmax}_{R m}[\mathrm{~mm}]$ & 1.67 & 0.37 & 1.49 & 0.34 & 0.001 \\
\hline $\operatorname{Gmax}_{R x}[\mathrm{~mm}]$ & 1.58 & 0.31 & 1.48 & 0.30 & 0.003 \\
\hline$Z_{R}[\mathrm{~mm}]$ & 3.45 & 0.69 & 3.41 & 0.76 & 0.030 \\
\hline$K_{R}[\mathrm{~mm}]$ & 0.61 & 0.01 & 0.65 & 0.01 & 0.103 \\
\hline$F_{R}$ & 1.67 & 0.67 & 1.49 & 0.71 & 0.011 \\
\hline
\end{tabular}

- male skulls, + - female skulls, $X$ - arithmetic mean, $S D$ - standard deviation, $p$ - significance level. Statistically significant values for Student $t$-test and Mann-Whitney* $U$ test $(p<0.05)$ 
After normalization by arithmetic modules, the excavations $\left(\max _{R m^{\prime}}, G \max { }_{R x}\right)$, circularity deviation and functional $\left(Z_{R}\right.$ and $\left.F_{R}\right)$ were of higher value in male skulls. For variables describing right orbit height $\left(\mathrm{Hmf}_{\mathrm{e}} \mathrm{k}_{\mathrm{R}}\right.$ and $\left.\mathrm{Hmax}_{R}\right)$ and for maximal elevation towards mean and median circle $\left(W_{\max _{R m}}\right.$ and $\left(\max _{R x}\right)$, as well as for circularity index $\left(K_{R}\right)$, statistically significant differences were not found (Table II). All remaining parameters were higher in female skulls.

As a result of normalization by the geometric modules, higher values for all parameters describing size and shape of the right orbit in the female group were obtained, except for $\operatorname{Gmax}_{R m}, \operatorname{Gmax}_{R x}$ and $F_{R}$. Parameters describing orbit height $(H m f-$ $e k_{R}$ and $\operatorname{Hmax}_{R}$ ), as well as maximal elevation towards median and mean circle $\left(W_{\max _{R m}}\right.$ and $W_{\max }{ }_{R x}$ and $K_{p}$ index, did not show statistically significant differences in comparison of male and female skulls (Table III).

\section{Left orbit parameters in male and female skulls}

The analysis of the left orbit outcome, including its area $\left(P_{L}\right)$, circumference $\left(O_{L}\right)$, reference circle radius, parameter describing height between two points ( $m f$ and $e k$ ) as well as maximal width and maximal excavation in relation to median and mean, circularity deviation, p2a indicator and functional, demonstrated a statistically significant higher parameter in the male group. The juxtaposition of differences in features characteristic of the left orbit shape and size in men and women showed a statistically significant difference in all compared parameters, except for Seor-ior,$H m f$-ek $k_{L}$, $H \max _{L}, W \max _{L m}$ and $W_{\max }$ (Table IV).

After normalization by the arithmetic modules, it was observed that $\operatorname{Gmax}_{L m}, \operatorname{Gmax}_{L x}, Z_{L}$ and $F_{L}$ present lower values in female crania. On the other hand, width (Seor-ior ${ }_{L}$ ), height (Hmf-ek and $\left.H \max _{L}\right)$ and excavations $\left(W_{\max }^{L}, W \max _{L x}\right)$ did not show a statistically significant difference between sexes (Tables $\mathrm{V}$ and $\mathrm{VI}$ ).

After normalization by the geometric module, lower values were obtained in the female group for the following variables: $\max _{L m}, \operatorname{Gmax}_{L x}$ and $F_{L \text {. }}$. With respect to parameters describing height of the orbit and its maximal elevation, no statistically significant differences were observed (Table VI). It was noted, however, that for all three types of results (without normalization, with normalization after the arithmetic modulus, and with normalization after the geometric module) the parameters characterizing the orbit height did not differ significantly between the male and female group. There is a difference for these variables describing

Table III. Right orbit size and shape parameters (RO), normalized results in accordance with geometric modulus

\begin{tabular}{|c|c|c|c|c|c|}
\hline \multirow{2}{*}{$\begin{array}{l}\text { Parameters } \\
\text { RO }\end{array}$} & \multicolumn{2}{|c|}{$\hat{0}$} & \multicolumn{2}{|c|}{ q } & \multirow[t]{2}{*}{ Value of $p$} \\
\hline & $x$ & SD & $x$ & SD & \\
\hline$P_{R}\left[\mathrm{~mm}^{2}\right]$ & 16.36 & 1.89 & 17.39 & 1.85 & 0.002 \\
\hline$O_{R}[\mathrm{~mm}]$ & 1.73 & 0.10 & 1.89 & 0.10 & 0.001 \\
\hline$R_{R m}[\mathrm{~mm}]$ & 0.27 & 0.02 & 0.29 & 0.01 & 0.002 \\
\hline$R_{R x}[\mathrm{~mm}]$ & 0.27 & 0.02 & 0.29 & 0.02 & 0.003 \\
\hline Seor-ior $_{R}^{*}[\mathrm{~mm}]$ & 0.56 & 0.06 & 0.60 & 0.11 & 0.001 \\
\hline$S m f-e k_{R}[\mathrm{~mm}]$ & 0.55 & 0.03 & 0.59 & 0.04 & 0.001 \\
\hline $\operatorname{Smax}_{R}[\mathrm{~mm}]$ & 0.60 & 0.04 & 0.65 & 0.04 & 0.011 \\
\hline$H m f-e k_{R}[\mathrm{~mm}]$ & 0.47 & 0.03 & 0.52 & 0.03 & 0.322 \\
\hline $\operatorname{Hmax}_{R}[\mathrm{~mm}]$ & 0.50 & 0.04 & 0.55 & 0.04 & 0.224 \\
\hline$W_{\max }^{R m}[\mathrm{~mm}]$ & 0.04 & 0.01 & 0.05 & 0.02 & 0.671 \\
\hline$W_{\max }^{R x}[\mathrm{~mm}]$ & 0.04 & 0.01 & 0.05 & 0.01 & 0.456 \\
\hline $\operatorname{Gmax}_{R m}[\mathrm{~mm}]$ & 0.04 & 0.01 & 0.03 & 0.01 & 0.001 \\
\hline $\operatorname{Gmax}_{R x}[\mathrm{~mm}]$ & 0.04 & 0.01 & 0.03 & 0.01 & 0.003 \\
\hline$Z_{R}[\mathrm{~mm}]$ & 0.08 & 0.02 & 0.09 & 0.02 & 0.030 \\
\hline$K_{R}[\mathrm{~mm}]$ & 0.01 & 0.00 & 0.02 & 0.00 & 0.103 \\
\hline$F_{R}$ & 0.04 & 0.02 & 0.03 & 0.02 & 0.011 \\
\hline
\end{tabular}

$\delta$ - male skulls, $q$ - female skulls, $X$ - arithmetic mean, SD - standard deviation, $p$ - significance level. Statistically significant values for Student $t$-test and Mann-Whitney* $U$ test $(p<0.05)$ 
Table IV. Parameters of size and shape of left orbit (LO)

\begin{tabular}{|c|c|c|c|c|c|}
\hline \multirow{2}{*}{$\begin{array}{l}\text { Parameters } \\
\text { RO }\end{array}$} & \multicolumn{2}{|c|}{$\hat{\sigma}$} & \multicolumn{2}{|c|}{ q } & \multirow[t]{2}{*}{ Value of $p$} \\
\hline & $x$ & SD & $x$ & SD & \\
\hline$P_{L}\left[\mathrm{~mm}^{2}\right]$ & 1139.10 & 123.76 & 1086.77 & 118.19 & 0.004 \\
\hline$O_{L}[\mathrm{~mm}]$ & 123.25 & 6.77 & 120.12 & 6.76 & 0.002 \\
\hline$R_{L} m[\mathrm{~mm}]$ & 18.94 & 1.02 & 18.41 & 0.97 & 0.001 \\
\hline$R_{L x}[\mathrm{~mm}]$ & 18.84 & 1.02 & 18.40 & 1.00 & 0.004 \\
\hline Seor-ior ${ }_{L}^{*}[\mathrm{~mm}]$ & 40.07 & 4.64 & 38.65 & 7.09 & 0.102 \\
\hline Smf-ek $[\mathrm{mm}]$ & 38.56 & 2.31 & 36.88 & 2.53 & 0.001 \\
\hline $\operatorname{Smax}_{L}[\mathrm{~mm}]$ & 42.13 & 2.46 & 41.14 & 2.70 & 0.010 \\
\hline$H m f-e k_{L}[\mathrm{~mm}]$ & 33.87 & 2.24 & 33.85 & 2.24 & 0.954 \\
\hline $\operatorname{Hmax}_{L}[\mathrm{~mm}]$ & 36.28 & 2.50 & 35.88 & 2.48 & 0.275 \\
\hline$W_{\max }[\mathrm{mm}]$ & 2.73 & 0.82 & 2.77 & 0.85 & 0.801 \\
\hline$W_{\max }[\mathrm{mm}]$ & 2.83 & 0.71 & 2.77 & 0.75 & 0.555 \\
\hline $\operatorname{Gmax}_{L m}[\mathrm{~mm}]$ & 2.66 & 0.75 & 2.21 & 0.64 & 0.001 \\
\hline $\operatorname{Gmax}_{L x}[\mathrm{~mm}]$ & 2.56 & 0.61 & 2.21 & 0.52 & 0.001 \\
\hline$Z_{L}[\mathrm{~mm}]$ & 5.40 & 1.14 & 4.99 & 1.09 & 0.014 \\
\hline$K_{L}[\mathrm{~mm}]$ & 1.06 & 0.01 & 1.05 & 0.01 & 0.033 \\
\hline$F_{L}$ & 2.41 & 1.07 & 1.92 & 0.90 & 0.001 \\
\hline
\end{tabular}

$\delta$ - male skulls, + - female skulls, $X$ - arithmetic mean, SD - standard deviation, $p$ - significance level. Statistically significant values for Student $t$-test and Mann-Whitney* $U$ test $(p<0.05)$

Table V. Left orbit size and shape parameters (LO), normalized results in accordance with arithmetic modulus

\begin{tabular}{|c|c|c|c|c|c|}
\hline \multirow{2}{*}{$\begin{array}{l}\text { Parameters } \\
\text { RO }\end{array}$} & \multicolumn{2}{|c|}{$\hat{0}$} & \multicolumn{2}{|c|}{ q } & \multirow[t]{2}{*}{ Value of $p$} \\
\hline & $x$ & SD & $x$ & SD & \\
\hline$P_{L}\left[\mathrm{~mm}^{2}\right]$ & 663.15 & 72.05 & 668.78 & 72.73 & 0.004 \\
\hline$O_{L}[\mathrm{~mm}]$ & 71.75 & 3.94 & 73.92 & 4.16 & 0.002 \\
\hline$R_{L} m[\mathrm{~mm}]$ & 11.03 & 0.59 & 11.33 & 0.60 & 0.001 \\
\hline$R_{L x}[\mathrm{~mm}]$ & 10.97 & 0.59 & 11.32 & 0.62 & 0.004 \\
\hline Seor-ior ${ }_{L}^{*}[\mathrm{~mm}]$ & 23.33 & 2.70 & 23.78 & 4.36 & 0.102 \\
\hline Smf-ek $[\mathrm{mm}]$ & 22.45 & 1.34 & 22.70 & 1.56 & 0.001 \\
\hline$S \max { }_{L}[\mathrm{~mm}]$ & 24.53 & 1.43 & 25.32 & 1.66 & 0.010 \\
\hline$H m f-e k_{L}[\mathrm{~mm}]$ & 19.72 & 1.30 & 20.83 & 1.38 & 0.954 \\
\hline $\operatorname{Hmax}_{L}[\mathrm{~mm}]$ & 21.12 & 1.46 & 22.08 & 1.53 & 0.275 \\
\hline$W_{\max }{ }_{L m}[\mathrm{~mm}]$ & 1.59 & 0.48 & 1.70 & 0.52 & 0.801 \\
\hline$W \max _{L x}[\mathrm{~mm}]$ & 1.65 & 0.41 & 1.70 & 0.46 & 0.555 \\
\hline $\operatorname{Gmax}_{L m}[\mathrm{~mm}]$ & 1.55 & 0.44 & 1.36 & 0.39 & 0.001 \\
\hline $\operatorname{Gmax}_{L x}[\mathrm{~mm}]$ & 1.49 & 0.36 & 1.36 & 0.32 & 0.001 \\
\hline$Z_{L}[\mathrm{~mm}]$ & 3.14 & 0.66 & 3.07 & 0.67 & 0.014 \\
\hline$K_{L}[\mathrm{~mm}]$ & 0.62 & 0.01 & 0.65 & 0.01 & 0.033 \\
\hline$F_{L}$ & 1.40 & 0.62 & 1.18 & 0.55 & 0.001 \\
\hline
\end{tabular}

$\delta$ - male skulls, $q$ - female skulls, $X$ - arithmetic mean, $S D$ - standard deviation, $p$ - significance level. Statistically significant values for Student $t$-test and Mann-Whitney* $U$ test $(p<0.05)$ 
Table VI. Left orbit size and shape parameters (LO), normalized results in accordance with geometric modulus

\begin{tabular}{|c|c|c|c|c|c|}
\hline \multirow{2}{*}{$\begin{array}{l}\text { Parameters } \\
\text { RO }\end{array}$} & \multicolumn{2}{|c|}{$\hat{0}$} & \multicolumn{2}{|c|}{ 우 } & \multirow[t]{2}{*}{ Value of $p$} \\
\hline & $x$ & SD & $x$ & SD & \\
\hline$P_{L}\left[\mathrm{~mm}^{2}\right]$ & 15.82 & 1.72 & 16.87 & 1.83 & 0.004 \\
\hline$O_{L}[\mathrm{~mm}]$ & 1.71 & 0.09 & 1.86 & 0.10 & 0.002 \\
\hline$R_{L m}[\mathrm{~mm}]$ & 0.26 & 0.01 & 0.29 & 0.02 & 0.001 \\
\hline$R_{L x}[\mathrm{~mm}]$ & 0.26 & 0.01 & 0.29 & 0.02 & 0.004 \\
\hline Seor-ior ${ }_{L}^{*}[\mathrm{~mm}]$ & 0.56 & 0.06 & 0.60 & 0.11 & 0.102 \\
\hline Smf-ek $[\mathrm{mm}]$ & 0.54 & 0.03 & 0.57 & 0.04 & 0.001 \\
\hline $\operatorname{Smax}_{L}[\mathrm{~mm}]$ & 0.58 & 0.03 & 0.64 & 0.04 & 0.010 \\
\hline$H m f-e k_{L}[\mathrm{~mm}]$ & 0.47 & 0.03 & 0.53 & 0.03 & 0.954 \\
\hline $\operatorname{Hmax}_{L}[\mathrm{~mm}]$ & 0.50 & 0.03 & 0.56 & 0.04 & 0.275 \\
\hline$W_{\max }^{L m}[\mathrm{~mm}]$ & 0.04 & 0.01 & 0.04 & 0.01 & 0.801 \\
\hline$W_{\max }[\mathrm{mm}]$ & 0.04 & 0.01 & 0.04 & 0.01 & 0.555 \\
\hline $\operatorname{Gmax}_{L m}[\mathrm{~mm}]$ & 0.04 & 0.01 & 0.03 & 0.01 & 0.001 \\
\hline $\operatorname{Gmax}_{L x}[\mathrm{~mm}]$ & 0.04 & 0.01 & 0.03 & 0.01 & 0.001 \\
\hline$Z_{L}[\mathrm{~mm}]$ & 0.07 & 0.02 & 0.08 & 0.02 & 0.014 \\
\hline$K_{L}[\mathrm{~mm}]$ & 0.01 & 0.00 & 0.02 & 0.00 & 0.033 \\
\hline$F_{L}$ & 0.03 & 0.01 & 0.02 & 0.01 & 0.001 \\
\hline
\end{tabular}

the orbit width, for Smf-ek and for Smax. Moreover, in female crania higher values for normalized results were recorded. Also, the left orbit functional in female crania was always of lower value both before and after normalization. The values of area, circumference and radii $\left(R_{L m}\right.$ and $\left.R_{L x}\right)$ were always higher in female crania compared to male crania. After normalization through the geometric module, circularity deviation revealed higher values in the female group, but before normalization as well as after normalization through the arithmetic modules, higher values of circularity deviation in the male group were observed. Orbit width (Smf-ek and $S_{\max }$ ) was statistically more significant and higher after normalization through both modules in female crania. Maximal excavation ( $\left.\max _{L m}, G_{\max }{ }_{L x}\right)$ demonstrated lower values in the female group both before and after normalization. Circularity deviation was statistically significant and higher in the female group only after normalization through the geometric module. The circularity index for the left orbit was lower in female crania before normalization, whereas the functional showed statistically significant higher values in all three types of results.

\section{Discussion}

Digital analysis of the orbits is a modern issue, but in the contemporary anthropological literature it is not sufficiently emphasized. Changeability of the orbit shape, and especially of the orbit inlet, is crucial for anthropologists and maxillofacial surgeons. Many attempts have been made to analyze the orbit, variability of its position, the shape and volume [11-13] by means of various tools. Up till now, the orbits have been measured using classic anthropometric utensils. These classic measurements are burdened with errors resulting from construction of the applied instruments (objective error) and from experience of the researcher (subjective error) $[14,15]$. Hence, our attempt to create an application based on a digital analysis would allow precise and repeatable measurements of the orbits to be obtained. All research based on morphometric features resulting from digital transformation of pictures ensure more objective data in comparison with a classic anthropometric measuring technique. Furthermore, digital analysis also has the advantage of faster and simplified calculation. In the subject literature there is evidence in favor of efficiency of digital methods in comparison to the classic ones. In the study by Lascala et al. [16] skulls were measured with classic craniometric methods using a slide caliper (considering 13 parameters), then the crania were scanned using a specific technique of computed tomography (conical beam computed tomography-CBCT). This study confirmed digital efficiency in measuring the 
external surface of the cranium. Farkas et al. [17] compared the results of anthropometric methods (direct) and cephalometric (indirect). Because of anatomical properties of the orbital edge, especially of its zygomatic part, it has been admitted that the measurement error may exceed $0.5 \mathrm{~mm}$. For other structures this error equals $1 \mathrm{~mm}$. The application exhibited in the authors' work, DICA 2.0, is based on a digital analysis of two-dimensional photos. It makes full use of digital measurement techniques thanks to vector recording of shape and size of the orbit inlet. This increases precision to subpixel resolution. DICA 2.0 also allows one to calculate new qualitative parameters such as functional and quantitative parameters - orbit center of gravity for example. What is more, DICA 2.0 may help register skeletal data in order to catalogue anthropologic material along with all data concerning parameters of crania. Digital picture recording also enables repeated measurement that could be useful for other researchers or other computer applications. The purpose of the present study was to analyze the orbit inlet. Although the plane outline of the orbit pictured from the front does not represent its dimensional character, thanks to DICA 2.0 application the orbit analysis could be compared with other anthropological work on the orbit inlet. When comparing male and female skulls, as well as left and right side, significant differences were observed in the distance to craniometric points. A great majority of the examined parameters had higher values on the right side than on the left side of the cranium. The asymmetry was manifested in metrical and non-metrical characteristics, including in the orbit shape. In comparison of the right and left side, different types of asymmetry were obtained. Variables describing orbit width, including Smax and Smf-ek, its height (Hmax) and Hmf$e k$ and radii (mean and median), surface area and circumference, were all higher in males before normalizing the results. After normalization through the arithmetic and geometric modules, the above values of measurements were significantly higher in female crania. It is worth emphasizing that female crania were bigger than male crania, which is also reported in the literature [18]. Nagle et al. [19] found, however, that the parameters characterizing width and height were of higher value in males. Nonetheless, the measurement was made on living people and not on skulls as such, and the obtained results were not normalized. The present study demonstrated that female crania had lower values for the functionals in both orbits in comparison to male crania. This makes it possible to classify orbit shape in female crania as rounder and in males as more rectangular. A round orbit shape in female crania is confirmed in the work of Patnaik et al. [20] and Wierciński's work [21].
According to Wierciński, the reason for these morphological differences in male and female skulls is the earlier and stronger ontogenetic retardation. In consequence female skulls morphologically resemble more skulls of children that have a rounder orbit shape. The study also demonstrated that in female skulls circularity deviation and excavations $G_{\max }$ and $G_{\max }$ were of lower value, which allows one to conclude that the orbit shape is closer to a reference shape of a circle. It should be emphasized that the value of the functional does not depend on orbit rotation, but on orbit shape. The parameters of the most important interest are those characterizing the orbit shape. Variables $G_{\max }$ and Gmax $_{R x}$ describing orbit shape inform about the degree of its deviation from the reference shape, that is from a circle. As it has already been mentioned, the analysis demonstrated that these values were lower in female skulls. In male skulls the orbits are of lower height and are more rectangular. The stated differences are consistent with literature data $[19,22]$. Symmetry, bone fault, bone separation and their reposition are evaluated during operation or diagnostic procedures. However, sometimes such points as the nasion and measurement of maximal width or orbit height are employed. The main anthropometric points are mainly used for body identification, scientific purposes and anthropometric surveys.

In conclusion, the obtained results confirm the existence of differences between male and female skulls. The orbit inlet shape in the female group is rounder than in the male group. Precision of the applied measurement method is of great importance for reconstructive surgery of the face.

\section{References}

1. Bron AJ, Tripathi BJ. Wollf's anatomy of the eye and orbit. Chapmann \& Hall, London 1997; 1-17.

2. Weisman RA. Surgical anatomy of the orbit. Otolaryngol Clin North Am 1988; 21: 1-12.

3. Lanz J, Wachsmuth W. Praktische Anatomie. Ein Lehrbuch und Hilsfbuch der anatomischen Grundlagen artlichen Handelns. T.l., Kopf; Berlin 1979.

4. Picket MM. L'indice orbitaire et l'apreciation de la largeur de l'orbite. Bulletin de la Societe d'Antropologie 1954; 10: 100-12.

5. Reymond J, Piasecki K. Cranioscopy and orbit injuries [Polish]. Czas Stomat 1988; XLI 9: 555-8.

6. Piasecki K, Reymond J, Wysocki J. Kształt wejścia do oczodołu - metodyka badań. In: Malinowski A, Łuczka B, Grabowski J. Antropologia a medycyna i promocja zdrowia [Polish]. Wyd. Uniw. Łódzkiego, Łódź 1996.

7. Patnaik VVG, Bala S, Singla Rajan K. Anatomy of the bony orbit-some applied aspects. J Anat Soc India 2001; 50: 59-67.

8. Zoll-Adamikowa M. Early medieval burial grounds of Małopolska Region. Part I [Polish]. Cz. I. Zakład Narodowy im. Ossolińskich, Wydawnictwo Polskiej Akademii Nauk, Wrocław-Warszawa-Kraków 1996: 61-2. 
9. Jankowski M. Elements of computer graphics [Polish]. Warszawa WNT 1990.

10. Lepich T, Dąbek J, Stompel D, Gielecki J. Analysis of the uppermassif of the craniofacial with the radialmethod - practical use. Arch Med Sci 2011; 7: 870-6.

11. Reymond J, Piasecki K. Craniofacial - object of antropological and medical studies [Polish]. Czas Stomat 1988; XLI: 503-4.

12. Forbes G, Gehring DG, Gorman CA, Brennan MD, Jackson IT. Volume measurements of normal orbital structures by computed tomographic analysis. Am J Roentgenol 1985; 145: 149-54.

13. Haas A, Weiglein A, Faschinger C, Mullner K. Fetal development of the human orbit. Graefe's. Arch Clin Exp Ophthalmol 1993; 231: 217-20.

14. Piasecki K. Las nuevas escalas craneoscopicas. observaciones preliminares. 1992 UW.

15. Perini TA, de Oliveira GL, dos Santos Ornellas J, de Oliveira FP. Technical error of measurement in anthropometry. Rev Bras Med Esporte 2005; 11: 86-90.

16. Lascala CA, Panella J, Marques MM. Analysis of the accuracy of linear measurements obtained by cone beam computed tomography. Dentomaxillofac Radiol 2004; 33: 291-4.

17. Farkas LG, Tompson BD, Katic MJ, Forrest CR. Differences between direct (anthropometric) and indirect (cephalometric) measurements of the skull. J Craniofac Surg 2002; 13: 105-8.

18. Brown P, Maeda T. Post Pleistocene diachronic change in East Asian facial skeletons: the size, shape and volume of the orbit. Anthropol Sci 2004; 112: 29-40.

19. Nagle E, Teibe U, Kapoka D. Craniofacial anthropometry in a group of healthy Latvian residents. Acta Medica Lituanica 2005; 12: 47-53.

20. Patnaik VVG, Bala S, Singla Rajan K. Anatomy of the bony orbit-some applied aspects. J Anat Soc India 2001. 50: 59-67.

21. Wiercinski A. Ontogenetic retardations and human evolution. Proc Symp Natur Select, Libice C.S.V., Prague 1978; 277-301.

22. Radović Z, Muretić Ž, Nemirovskij V, Gaži-Čoklica V. Craniofacial variations in a South Dalmatian population. Acta Stomatologica Croatica 2000; 34: 399-403. 